\title{
The competence that satisfy us: agribusiness and airlines business management cases
}

\author{
Kannapat Kankaew, ${ }^{1, *}$ \\ ${ }^{1}$ International College, Suan Sunandha Rajabhat University, 1 U-Thong Nok rd, 10200, Dusit, \\ Bangkok, Thailand
}

\begin{abstract}
The airline is one of the highly intense competition, in the meantime it is the most vulnerable industry to external environment.Importantly, the service quality is remarkably affecting to the customer's preference choosing to fly. This study aims to assess the competencies of ground service agent that affecting passenger's satisfaction. The quantitative method was applied. The descriptive statistic, factor analysis, multiple regression, and structural equation modelling were administered. The data collected by using questionnaires from 800 passengers. The sample group divided into two groups including 400 passengers who use low-cost airline, and 400 passengers who use fullservice airline operating in Thailand. The results found that the most prefer competencies from the passenger are understanding the cultural diversity with continuous learning to achieving the career path, having serviceoriented mind with ethics and morals, and having a good social interaction and teamwork.
\end{abstract}

\section{Introduction}

The extreme competition in airline industry enforces air carriers to adapt strategies, innovate new products and services, reduce operating cost, building relationship with agents, or to merge with each other. These are allowing airlines to be competitive [1]. At the same time, airlines need to balance the interaction with customer, and the treat of its employees. Particularly, the frontline employees since the quality of people, and process are the key competitive advantage among airlines. Since, the services provide by air carrier different from other products with four distinct characteristics including, intangibility, variability quality, and perishability. Thus, a competence of people will deliver extraordinary and memorable service quality [2].

In addition, the frontline employees who put on the airline's uniform act as the mobile advertisement of an organization [3]. Hence, [4] suggested that the management should improve the service quality by delivering the effective responsiveness. However, both the management team and employees need to clearly understand the service quality and responsiveness in airline services. Due to, the words responsiveness is too vague to the employees to practice. From this reason, it is important to upgrade service quality to meet

\footnotetext{
${ }^{*}$ Corresponding author: kunnapat.ka@ssru.ac.th
} 
the needs of passenger for the competitive advantage. Furthermore, it is mandatory for management to understand the service quality definition precisely, so that the airline will know how to satisfy its customer. Albeit, the authors view that the organization also has to understand the customer needs, and identify the competency that the clients reckon important to satisfy them. As a result, it will be easier for airline to find the right candidates, and develop existing employees to be skillful purposefully for the service. Then, this research aims to identify the competencies of ground service agent from the passenger's perspective resulting to better serve and satisfy them. It will be also easier for airline setting the development objectives.

\section{Literature reviews}

The service quality has long been studied to satisfy the customers. As [3] said that the customer who delight with the service could become loyalty, referee to others, that is resulting to firm's revenue, stock price, and economic as a whole. While, today products and services are becoming quite the same [5]. Specifically, the airline's productsand services, then the experience of customer receiving from the service provider cold make airline distinct. Considering that, presently, the knowledge-based society the demands and expectations of passengers are upsurge. So that, it is not easy for airlines to satisfy the passenger [6].

As refer to [5] reviewed the evaluation tools for improving service quality, and managing customer experience. The widely used namely the SERVQUAL. It was generated by Parasuraman et al in 1988. The tool composes of five dimensions including, reliability, responsiveness, assurance, empathy, and tangibility. These five dimensions can be explained that the reliability refers to the capability of service provider can be trust, and accurate as promised to the customer. The second, responsiveness defines as the eagerness of service provider helping the client, prompt service, a good attitude towards customer demands. The third, assurance is abroad-spectrum capable of building trust and confidence to the customer on the organization. The fourth, empathy refers to the assessment of individual needs, understand, attentive to customer and sought to provide for each individual. And last dimension is tangibility relates to the appearance of physical form of the services that can be seen [7].

The SERVQUAL model was applied in various service firms, as well as in the airline companies for example; [8] applied SERVQUAL dimension to study the job design in airline companies could motivate employees to deliver better services. The researchers recommended airlines to socialize employees, allow them to interact with passengers. It would raise the motivation to work more effective.

Where, [9] adapted the SERVQUAL model to AIRQUAL dimension for specific study in the airline services. The AIRQUAL consists of airline tangibles, terminal tangibles, personnel services, empathy, and airline image.The result, they suggested airlines to create a unique strategy, select the person fit with the position who is good looking personality and grooming, then training to focus on the customer empathy, personalized services. While, [10] also used AIRQUAL conducting the study on airline service quality. The researchers found that the factors affecting passenger's satisfaction were the attitude of employees, the knowledge and experiences of employees, and the empathy services.Actually, the service quality evaluation of an airline is complex, since there are various services different among airlines across the globe, and the terminal tangibles concern with the airport operator [11].

In these regard [12] advised organization to create the customer-centric culture. The first thing is to cultivate empathy concept in every part of customer operation within 
organization. The second is to employ the individual who has a customer service-minded. The later thing is allowing everyone able to access the customer data.

The fourth is to expedite staff having direct interaction with customer, so that they can learn from the customer. Then, aligning the employee culture to customer outcomes reflecting the customer-centric culture. This might be related with the experience and satisfaction of customer. And last, the organization should link the pay for performance by using customer-centric approach, such as the ability to keep existing customer. It is the fact that each individual does not hold the same skills, knowledge, and ability.

Along these lines, organization has to identify the competencies and training requirements for all employees. The competenciesdetermined as a set of behavior that can be observed through the job performance including, knowledge, skills, attitude, traits, and motivation at individual, team and organizational level.

The organization that lack of competencies development, or having limited competencies could lose competitive advantage [13]. During the time [14] determined the competencies for service job including, ability to building trust, using verbal and nonverbal language, having innovative coaching skills, flexible, self-assure, interpersonal skills, empathetic, listening skills, emotional quotient, problem-solving, teamwork, professional expertise, analytical thinking, and assertiveness. Where [15] added the diversity cultural knowledge, effective communication skills, positive attitude are essential for the frontline employees.

From the mentioned above the authors have identified fourteen competencies in the conceptual framework for this study as shown in figure 1 .

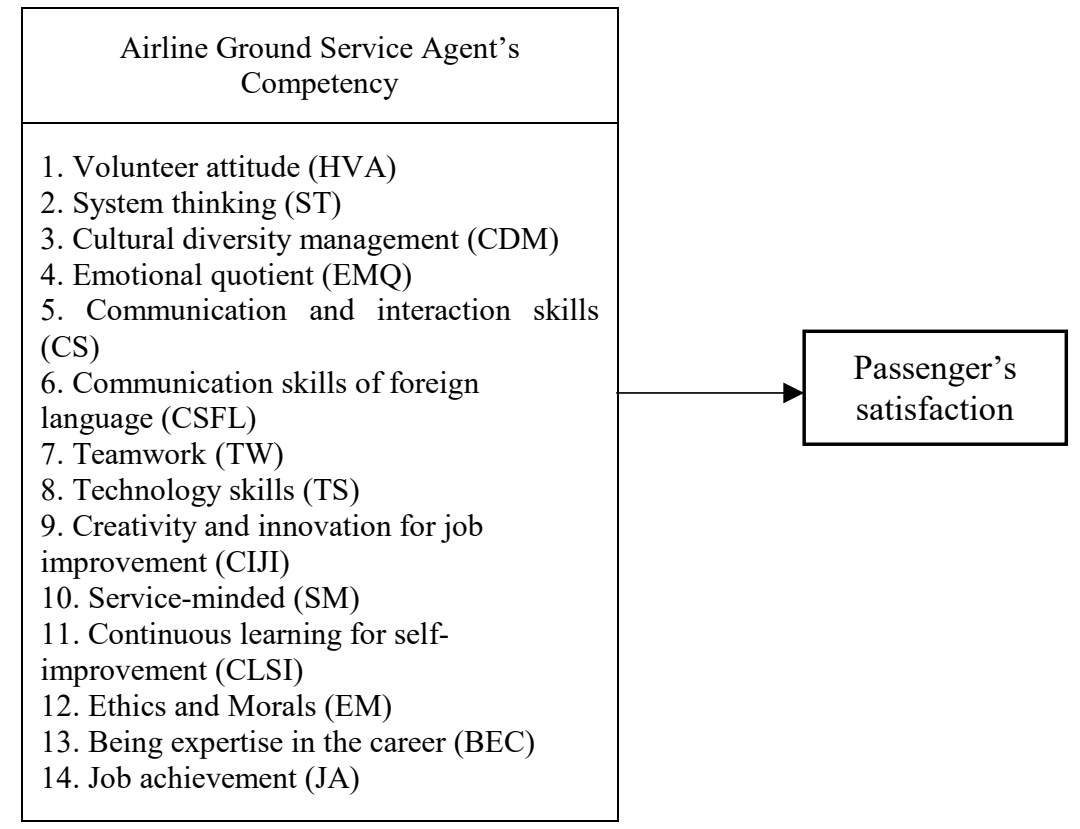

Fig. 1. Conceptual Framework.

\section{Aim of the research}

This study aims to assess the competencies of ground service agent that affecting passenger's satisfaction. The anticipate result, airline companies could apply to develop their ground service agent to be more competence delivering better services. 


\section{Methodology}

A quantitative method was administered of this study, the researcher employed, SPSS for descriptive analysis, factor analysis, multiple regression, and structural equation modelling to test path analysis correlation between ground service agent's competencies and passenger's satisfaction. The fitness index was tested; including Chi square $<5.00$, GFI $>$ 0.96 , NFI RFI, CFI and RMSEA $<0.087$. $\geq 0.98, \geq 0.95 \geq 0.97$. The sample comprises of 400 passengers who use full-service airlines at Suvarnabhumi International Airport (BKK), Another 400 passengers who use low-cost airlines operating at Don Mueang International Airport (DMK) in Thailand. The data was collected by using questionnaires. The convenience sampling was employed for data collection.

\section{Results}

Most of the respondents were female accounted for 61 percent, and 39 percent were male. The majority of sample aging around 24-29 years old, 30-35 years old, and 18-23 years old accounted for 32.3 percent, 26.8 percent and 12.5 percent respectively. The highest education level was master degree accounted for 20.5 percent, bachelor degree 50 percent, and diploma level 6.5 percent. The Cronbach's alpha coefficient; $\alpha$ was tested, and the result score was at 0.915 level.Researchers have compared the perspectives of respondents who used full-service airlines and low-cost airlines on the competencies that most fit for ground service agent as shown in table 1 below;

Table 1. Competencies of ground service agent from passenger's perspective.

\begin{tabular}{|l|c|c|c|c|}
\hline \multirow{2}{*}{\multicolumn{1}{|c|}{ Competencies }} & \multicolumn{2}{c|}{ Full-service } & \multicolumn{2}{c|}{ Low-cost } \\
\cline { 2 - 5 } & mean & SD & Mean & SD \\
\hline 1. Volunteer attitude & 4.35 & .583 & 4.38 & .555 \\
\hline 2. System thinking & 3.84 & .633 & 3.85 & .613 \\
\hline 3. Cultural diversity management & 4.21 & .536 & 4.24 & .508 \\
\hline 4. Emotional quotient & 3.91 & .616 & 3.95 & .605 \\
\hline 5. Communication and interaction skills & 4.22 & .619 & 4.27 & .569 \\
\hline 6. Communication skills of foreign language & 4.28 & .586 & 4.30 & .546 \\
\hline 7. Teamwork & 4.09 & .685 & 4.12 & .676 \\
\hline 8. Technology skills & 4.53 & .537 & 4.55 & .500 \\
\hline 9. Creativity and innovation for job improvement & & & & \\
\hline 10. Service-minded & 4.50 & .581 & 4.56 & .515 \\
\hline 11. Continuous learning for self-improvement & 4.60 & .522 & 4.64 & .465 \\
\hline 12. Ethics and Morals & 4.46 & .552 & 4.49 & .500 \\
\hline 13. Being expertise in the career & 4.59 & .550 & 4.66 & .493 \\
\hline 14. Job achievement & 4.21 & .542 & 4.23 & .529 \\
\hline \multicolumn{1}{|c|}{ Total } & 4.20 & .593 & 4.27 & .579 \\
\hline
\end{tabular}

The result as illustrated in table 1, revealed that all fourteen competencies tend to be highly important to be instilled for a ground service agent of both full-service and low-cost airlines. Where the lowest scores are in the system thinking, and the emotional quotient respectively. Albeit, the authors employed the factor analysis to synthesize the real competencies affecting the satisfaction of passengers. Each of the competencies have included three variables to determine its characteristics.So, there are 42 components from 14 main competencies.Consequently, after the factor analysis have done the result was shown in table 2 below; 
Table 2. Factor loading after rotation competencies of ground service agent.

\begin{tabular}{|c|c|c|}
\hline Key Indicator Questions & $\begin{array}{c}\text { Factor } \\
\text { Loading }\end{array}$ & Competency Explanation \\
\hline Being honest and integrity in the profession & .815 & $\begin{array}{l}\text { 1. Service-minded, and Ethics } \\
\text { and Morals (SME) }\end{array}$ \\
\hline $\begin{array}{l}\text { Express and provide the service from the } \\
\text { within. }\end{array}$ & .809 & \\
\hline $\begin{array}{l}\text { To adhere and comply with professional ethics } \\
\text { and morals in the workplace }\end{array}$ & .807 & \\
\hline Mutual responsibility in the team & .835 & $\begin{array}{l}\text { 2. Communication, interaction } \\
\text { and teamwork (CTW) }\end{array}$ \\
\hline $\begin{array}{l}\text { Having the speaking techniques and being a } \\
\text { good listener. }\end{array}$ & .787 & \\
\hline $\begin{array}{l}\text { Having a good attitude towards teamwork and } \\
\text { cooperation }\end{array}$ & .807 & \\
\hline $\begin{array}{l}\text { The ability to control and manage self- } \\
\text { emotion. }\end{array}$ & .808 & 3. Emotional Quotient (EMQ) \\
\hline $\begin{array}{l}\text { The ability to build relationships and } \\
\text { friendliness to clients. }\end{array}$ & .797 & \\
\hline $\begin{array}{l}\text { The ability to adjust self in accordance with } \\
\text { the environment and the situation that occurred } \\
\text { positively. }\end{array}$ & .787 & \\
\hline $\begin{array}{l}\text { The ability to adapt the services in line with } \\
\text { cultural differences. }\end{array}$ & .740 & $\begin{array}{c}\text { 4. Cultural diversity } \\
\text { management, being expertise in } \\
\text { the career, job achievement } \\
\text { (CBJ) }\end{array}$ \\
\hline $\begin{array}{l}\text { Performing the assigned task according to the } \\
\text { international standards. }\end{array}$ & .733 & \\
\hline $\begin{array}{l}\text { Skill development to become an expert in the } \\
\text { job. }\end{array}$ & .687 & \\
\hline The willingness to provide service at all times. & .683 & $\begin{array}{l}\text { 5. Having volunteer attitude } \\
\text { (HVA) }\end{array}$ \\
\hline Enthusiastic in helping others all the time. & .635 & \\
\hline Work with the primary interest for others. & .595 & \\
\hline $\begin{array}{l}\text { The sought of learning about job, and duties } \\
\text { from electronic media continuously for self- } \\
\text { development. }\end{array}$ & .727 & $\begin{array}{l}\text { 6. Communication skills of } \\
\text { foreign language, continuous } \\
\text { learning for self-improvement } \\
\text { (FLSI) }\end{array}$ \\
\hline $\begin{array}{l}\text { The ability to communicate, understand } \\
\text { English correctly. }\end{array}$ & .680 & \\
\hline $\begin{array}{l}\text { The ability to communicate of foreignlanguage } \\
\text { at basic and advance level for customer } \\
\text { services. }\end{array}$ & .652 & \\
\hline
\end{tabular}

From table 2; it is revealed that 800 passengers who used full-service and low-cost airlines viewed that there are only 6 competencies important from 14 competencies. The authors have selected only top three observed variables most highly ranked in each of the 6 competencies, then rename the code of new 6 competencies that were chosen by the passengers. Meanwhile, the multiple regression was conducted to test the correlation of the competencies to passenger's satisfaction shown in table 3 as follow; 
Table 3. Ground service agent competencies affecting passenger's satisfaction.

\begin{tabular}{|c|c|c|c|c|c|}
\hline \multicolumn{2}{|c|}{ Competencies } & Passenger's satisfaction & $\mathbf{R}$ & $\mathbf{t}$ & $\mathbf{P}$ \\
\hline Constant & .820 & & .847 & 9.085 & \\
\hline \multicolumn{2}{|c|}{$\mathrm{CBJ}$} & Service quality & .061 & 3.382 & .001 \\
\hline \multicolumn{2}{|c|}{ HVA } & Responsiveness & .089 & 2.926 & .004 \\
\hline \multicolumn{2}{|c|}{ FLSI } & Reliability & .710 & 17.310 & .000 \\
\hline \multicolumn{2}{|c|}{$R^{2}=.718$} & Service meet expectation & & & \\
\hline \multicolumn{2}{|c|}{$\mathrm{F}=336.708$} & & & & \\
\hline
\end{tabular}

*Significant level 0.05

From table 3, it can be seen that there are only three competencies from factor analysis having influence on passenger's satisfaction. The passenger's satisfaction composed of four variables including, service quality, responsiveness, reliability, and the service that meet expectation.The competencies that most affecting to passenger's satisfaction are communication skills of foreign language, continuous learning for self-improvement (FLSI). The second is CBJ competency including, cultural diversity management, being expertise in the career, job achievement $[16,17]$. And the third is HVA refer to having volunteer attitude.

To be more concise of the result, the authors applied structural equation modelling to test path analysis as shown in figure 2 below;

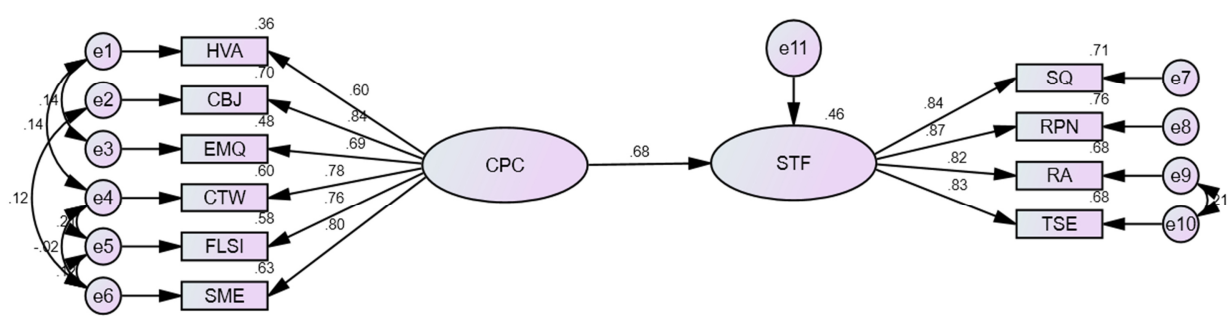

Fig. 2. Path analysis competencies of ground service agent with passenger's satisfaction.

From figure 2, it is remarkable that the highest weight score is on CBJ at 84 percent, the second is SME at 80 percent, the third is CTW accounted for 78 percent. Consequently, the overall of six ground service competencies have influenced on passenger's satisfaction 68 percent.

\section{Conclusion and recommendations}

In conclusion, a good service quality affecting to passenger's satisfaction to return using the airline. As a result, the loyalty customer will generate revenue, stock price and economic system as a whole. Especially, Thailand, where the highest revenue of the country come from tourism and hospitality. From the beginning, the authors have set fourteen crucial competencies and examine with foursteps including, descriptive analysis, factor analysis, multiple regression, and structural equation modelling. Finally, the test found that there are three most important competencies from a passenger's perspective to satisfy them. Those are CBJ, SME, and CTW respectively.

Thus, once the air carrier recruits and select the right candidates to work as a ground service agent. The process of training and developing should include six competencies in which the passenger's view important quality of ground service agent. There are having volunteer attitude, understanding the cultural diversity with continuous learning to achieving the career path, having emotional quotient, having a good social interaction and 
teamwork, the ability to communicate English for the service effectively, and having service-oriented mind with ethics and morals. While, the top three most competencies should be emphasized are understanding the cultural diversity with continuous learning to achieving the career path, having service-oriented mind with ethics and morals, and having a good social interaction and teamwork. It is in accordance with the SEM result shown in figure 2 .

Nevertheless, the limitation of this research is the sample groups were only Thais. For future study, the authors recommend to collect data from other nationalities.

\section{References}

1. L. Chen, Y-Q. Li, C-H. Lui, JATM 75, 185-197 (2019)

2. Airline marketing (IATA, 2013)

3. V.A. Zeithaml, M.J. Bitner, D.D. Gremler, Services marketing (2018)

4. F.T. Shah, Z. Syed, A. Imam, A. Raza, JATM 85 (2020)

5. D. Havir, EAB 31, 82-93 (2017)

6. M.S. Farooq, M. Salam, A. Fayolle, N. Jaafar, K. Ayupp, JATM 67, 169-180 (2018)

7. M. Woo, JATM 76, 40-47 (2019)

8. D. Ushakov, O. Yushkevych, N. Ovander, H. Tkachuk, V. Vyhovskyi, Geojournal of Tourism and Geosites XII(27/4), 1429 (2019)

9. K. Simsek, O. Demirbag, JISR 2, 11-29 (2018)

10. K.M. Koklic, M. Kukar-Kinney, S. Vegelj, JBR 80, 188-196 (2017)

11. M.G. Bellizzi, L. Eboli, G. Mazzulla, TRP 45, 218-225 (2020)

12. D.L. Yohn, 6 ways to build a customer-centric culture (2018) http://www.hbr.org

13. R. Laakso-Manninen, R. Viitala, Competence management and human resource development (2007)

14. M.L. Spencer, M.S. Spencer, Competence at work (1993)

15. R.C. Langes., F.N. Piercy, JSR 15, 215-230 (2012)

16. O. Decha, EUrASEANs 5(18), 65-78 (2019)

17. A. Př́ivara, Geographical Journal 71(2), 161-180 (2019) 